\title{
E-Readiness Framework for Corporate Online Reporting
}

\author{
Khaldoon Abed Al-Htaybat \\ Accounting and Finance Department, Al-Hussein Bin Talal University, Jordan \\ E-mail:kaah@ahu.edu.jo,khaldon77@yahoo.com
}

Received: May 3, $2011 \quad$ Accepted: June 1, $2011 \quad$ Published: October 1, 2011

doi:10.5539/ass.v7n10p68

URL: http://dx.doi.org/10.5539/ass.v7n10p68

\begin{abstract}
The purpose of this paper is to propose a contingency framework of e-readiness for corporate online reporting as a step towards establishing an e-readiness assessment methodology regarding corporate online reporting. This framework reflects the attempt to provide a theoretical background in the field. An extensive review of a number of instruments for assessing e-readiness as well as of other previously developed accounting frameworks was performed to identify the potential factors to be included in the proposed framework. Thirteen exploratory interviews and informal discussions were conducted with academics in the area of accounting and information technology and management information systems, and a pilot questionnaire survey was distributed to collect the perceptions of four different user-groups of corporate online reporting, (financial analysts, managers, bank credit officers and auditors) regarding the potential factors that should be included in the proposed framework. The contingency perspective was employed to integrate several internal and external factors in the form of the proposed framework. A framework was developed to integrate both endogenous and exogenous factors that recognise actual features regarding the e-readiness of corporate online reporting.
\end{abstract}

Keywords: E-readiness framework, Internet financial reports, Corporate online reporting

\section{Introduction}

The emergence of new technological innovations and the rapid growth of the Internet as a network communication around the world provide tremendous benefits to all aspects of society and have influenced the corporate financial reporting practices significantly (Hanafi, et al. 2009). This has increased the level of global competition among companies and has intensified their challenges to disseminate and maintain relevant information to meet the changing needs of interested users. In response to these challenges, corporate online reporting (COR) as a communication tool has emerged to interact with stakeholders (Jones and Xiao, 2003; Xiao et al., 2002). Various recent studies have investigated COR (see for instance Ettredge et al. (2002), Oyelere et al. (2003), Marston (2003), Marston and Polei (2004), Al-Htaybat and Napier (2006), Momany and Al-Shorman (2006), Andrikopoulos (2007), Bozcuk et al (2008), Desoky (2009), Despina and Demetrios (2009), Lai et al. (2010), Verma (2010), Aly et al. (2010), Al-Hayale (2010), Aziz and Salleh, 2011) but none of these have addressed the readiness of companies in terms of electronic aspects to adopt COR, otherwise referred to as e-readiness.

COR is considered as a communication system with the potential to affect the communicative aspects of financial reporting, such as accessibility from anywhere, the quantity of dissemination, presentation formats, integration and interaction with other technologies. Further, COR is considered to be entrepreneurial by nature, and is continuously recognized as crucial for society and the overall economy. Companies as well as interested users have the capacity to participate in the digital economy in order to take advantage of COR's potential by collecting, processing, using and utilizing digital information. Importantly, these studies have documented that although there is an increasing usage of COR, there is a clear variation in the level of COR practices among these countries. COR incorporates several elements or aspects that should be considered as challenges relating to its implementation such as the technology aspect, the infrastructures, human capital and organizational aspect. Companies in different countries are facing these challenges at different levels as there are internal variations within a country. The question here is how to make better use of COR, and whether the technological aspects that exist must be improved, other challenges such as companies' infrastructure, human skills and attitudes need to be addressed, or maybe all aspects have to be considered for COR's improvements. These aspects are referred to in this paper as electronic-readiness (e-readiness) aspects of COR. 
Therefore, this paper aims to review the extant literature on COR and proposes a contingency e-readiness framework as a step towards assessing the e-readiness of COR. The framework serves to integrate both endogenous and exogenous factors that recognise actual features regarding the e-readiness of COR.

\section{The rationale underlying COR's e-readiness framework}

E-readiness as a concept has been defined in the literature in different ways depending on the researchers' objective (Keoduangsine and Goodwin, 2009). It is defined by Choucri et al (2003, p.4) "as the ability to pursue value creation opportunities facilitated by the use of the Internet." E-readiness is defined as a valuable indicator for a nation's ability of using advanced technology and/or taking advantage of the Internet as an engine of human development and economic growth (Al-Solbi et al., 2005; Keoduangsine and Goodwin, 2009). Dada (2006) defines it as a measure of the degree to which an economy or nation is prepared to obtain benefits from information and communication technology (ICT) in the digital economy. According to Beig (2007) the concept of e-readiness was invented through efforts of development agencies, research organizations, academia, business enterprises and individuals. E-readiness is usually used to gauge a country's, nation's, economy's ability to partake in digital activities (Dada, 2006). Studies on e-readiness have been conducted towards assessing countries' e-readiness to benefit from ICT by using quantitative and qualitative indices to evaluate and rank countries on the e-readiness scale (Rizk, 2004).

This paper stresses the importance of assessing the e-readiness status for COR for the following reasons: companies around the world are increasingly using COR to improve their services and create new investment opportunities to have a competitive edge over those that are less COR oriented. E-readiness became, as the degree to which companies are prepared and have the potential to take advantage of COR, an important measure providing a set of valuable indicators able to identify companies' online ability and then assess the progress on e-readiness for COR. E-readiness is useful to assess and summarise the characteristics of COR's prepares and users to understand and identify the adequate ability and knowledge preparers and users should possess. This includes, for instance, the ability to collect, process, share and utilize digital information. It is important to develop an e-readiness assessment, especially if preparers and users of COR suffer from the digital divide or if they fail to provide an adequate ability and knowledge base to deal with COR. In these cases, they are not able to use COR appropriately to meet their needs, and they very likely fall behind on benefiting from and taking advantage of COR. E-readiness assessment methods are expected to help in the formulation of national action plans for interested parts in both developed and developing countries to enhance the e-readiness of COR's users. Therefore, in an effort to fill this gap, this paper will carry out the first attempt to develop a valid and reliable contingency framework regarding e-readiness of COR. The main aim of the next section is to review key prior studies of e-readiness assessment indices. Section 3 establishes the research method and discusses data collection. Section 4 presents the analysis of the data, and finally section 5 provides comments on the results and their implications.

\section{COR's e-readiness assessment methodology}

\subsection{Review of prior frameworks in accounting and financial reporting}

In order to ensure that the contingency framework regarding e-readiness of COR is developed according to reliable and valid sources, an extensive review was performed of prior frameworks that explain the main environmental factors influencing accounting and financial reporting practices. In the international literature of accounting research, accounting practices including management accounting in any country is shaped by its dynamic environmental forces and factors such as e.g. social, economic, culture, political, regulation, international trade and new technology developments, (Gray, 1988; Nobes, 1998; Roberts et al., 1998; Radebaugh and Gray, 2002). This suggests that the form and content of financial reporting at any time and in any place depends on both endogenous and exogenous factors that apply at that time and in that place. These factors are not static but change through time dynamically. As Roberts et al. (1998) and others have argued, changes in these factors themselves, and the actual accounting and reporting practices to be found, are subject to many factors, both internal and external to individual countries. These factors are summarised by Roberts et al. (1998) in a dynamic framework suggesting that the accounting system in practice reflects the influence of society, culture and other integrated factors in the form and content of both mandatory and voluntary accounting practices.

In the context of factors influencing accounting practices, Gray (1988) argued that, due to the external and internal forces, changes in society's structures happen to influence societal values, and then influence family patterns, social class structure, political systems, business ownership, organization, and educational systems, which will eventually influence accounting practices. Furthermore, in attempting to explain the environmental, 
technological and non-technological factors that may have impacted on the developments of accounting and financial reporting practices in a country, accounting scholars have examined a variety of these factors, such as social, economic, political and new technology developments including digital communication, Internet, mobile phones and other computer software technological developments (Radebaugh and Gray, 2002; Xiao et al, 1996; Xiao et al, 2003). Cooke and Wallace (1990) and Curuk (1999) combined several of these factors in Environmental Theory to explain the relationship between financial reporting practices and environmental factors. Table 1 summarizes the broad range of possible international and external environmental factors that might have an impact upon financial reporting, as discussed in prior studies, in particular Gray (1988), Cooke and Wallace (1990), Nobes (1998), Roberts et al. (1998), and Radebaugh and Gray (2002).

\section{Please insert Table 1 here}

The internal and external factors listed in Table 1 interact with each other at different levels according to their different environments to influence and to form the accounting systems, including financial reporting, differently across countries over time and according to the relative influence of these environments (see Radebaugh and Gray, 2002). For instance, culture is the strongest influential factor according to Gray (1988), as it has been shown to affect the structure of organizations and society (Hofstede and Bond, 1988). Cooke and Wallace (1990) concluded that financial reporting practices in many developed countries are a product of internal factors, whereas those of many developing countries are likely to be a product of external factors.

More recently, the developments of technological innovation have an intense effect on all aspects of society, including economic, political, and other infrastructures, and within the context of financial reporting, the Internet is considered as a potentially revolutionary method of financial communication (Xiao et al., 1996; Xiao et al. 2002; Jones and Xiao, 2003). Xiao et al. (1996 and 1997) used a contingency perspective based on the contingency theory of organization to propose a framework for evaluating the impact of information technology on corporate financial reporting which assumes that information technology has the potential to change different aspects of financial reporting, and that the degree and pattern of this impact are conditioned upon contingent cultural, economic, political, organizational and behavioral factors.

Based on the above, and for the purpose of this paper, it can be argued that accounting and financial reporting practices, specifically here COR, are subject to contingent factors. As prior studies have documented, there is a clear variation in the level of COR practices among countries (see for instance: Ettredge et al. (2002), Andrikopoulos (2007), Despina and Demetrios (2009), Lai et al. (2010) and Verma (2010)). This variation can be explained as follows: the implementation of COR in any country addresses several aspects that should be considered as challenges such as the technology aspect, countries' and companies' infrastructures, human skills, attitudes towards technology, and organizational aspect. Companies in different countries are facing these challenges at different levels as there are internal variations within a country. Therefore, this paper intends to develop a valid and reliable e-readiness framework as a first step to test the abilities of taking advantage of COR fully in any country around the world. In an effort to correctly build the current framework, the next section surveys the extant literature of e-readiness assessments of using ICT to establish a valid and reliable base of the endogenous and exogenous factors that recognise actual features regarding the e-readiness for COR in this paper.

\subsection{Review of prior research and models of e-readiness assessment}

Over the last decade there is a large amount of published and unpublished research in the area of e-readiness assessment. Several organizations, academics and researchers have developed different indices for e-readiness assessment to measure a country's or nation's e-readiness, of which each measure has different sub-points of e-readiness and provides different rankings and findings (Dada, 2006). These are reviewed in this section to give an overview of existing applications in the field and a critical review is undertaken to conclude the state of e-readiness in the context of COR.

Firstly, the Information Technologies Group, Center for International Development (CID) at Harvard University, develop an e-readiness assessment guide for developing countries on an annual base. Each guide of CID provides a broad framework with five categories of network variables that any developing economy can apply. There are five network indicators: access, learning, society, economy, and policy. The readiness is measured according to the degree to which a country is prepared to participate in the Networked World (CID, 2006).

In addition, the MOSAIC Group as part of the Global Diffusion of the Internet Project (GDI) developed a framework for assessing the GDI (Wolcott et al. 2001). This framework presents a comprehensive framework for describing the diffusion of the Internet within a country at a particular point of time by characterizing diffusion using six dimensions: pervasiveness, geography dispersion, sectoral absorption (usage within major sector of the 
economy), connectivity infrastructure, organizational infrastructure (the state of the internet service market) and sophistication of use (Wolcott et al. 2001).

Furthermore, McConnell International (LLC) developed the McConnell International (MI) tool. MI defines e-readiness as the capacity of nations to participate in the digital economy. The tool was developed to measure status and progress on five interrelated attributes with sub-indicators in parentheses: Connectivity (infrastructure, access and pricing), e-leadership (government policies and regulations), information security (intellectual property, privacy, electronic signatures), human capital (ICT education, available skilled workforce) and e-business climate (competition, political and financial stability, foreign investment, financial infrastructure) (McConnell International, 2000).

The review of these indices shows that most of these dealt with the overall e-readiness of countries on the macro level by focusing on infrastructure and technology, human skills, accessibility and connectivity of ICT at a specific point of time. The review also revealed that there is no unified e-readiness assessment measure. There are different assessment indices of national and international developments with different underlying objectives, definitions, and different weighted and un-weighted indicators of e-readiness. In this context, Beig (2007) argued that prior e-readiness assessments lack a one standard assessment policy that would provide unified assessment measures. Rizk (2004) stated that there are two main ways of assessing e-readiness on a macro level, the quantitative and qualitative approaches. In case of the former countries are ranked according to a weighted average of numerical scores based on the extent of their performance on specific indicators of the e-readiness index, see EUI e-readiness index. In case of the latter more focus was given to qualitative measures, ranking the indices indicators such as connectivity and human skills, see MI and WEF indices. Moreover, Rizk (2004) argued that macro level assessments allow for a general foundation of comparison across countries as the focus is on the general indicators for assessing macro e-readiness such as infrastructure/usage and education. Across countries, e-readiness studies applied one set of measures on several countries ignoring the internal variations within each country, and in some cases these studies used qualitative measures by using relative weights which may vary from one country to another (Rizk, 2004).

The above discussed prior studies are utilised in the next section to outline the framework of assessing e-readiness for COR. Several factors that were discussed above were modified to fit the COR picture, as shall be outlined next.

\subsection{Development of the current framework of e-readiness for COR}

For the purpose of this paper, it is important to clarify the definition of e-readiness before proceeding with any assessment. E-Readiness, in relation to COR, is defined here as: the adequate ability and knowledge in participating and taking advantage of COR through disseminating collecting, processing, sharing and utilizing information digitally. Therefore, the objective of this paper is to carry out an e-readiness assessment to gauge how ready companies are to benefit from COR. In order to accomplish this objective, a framework of factors influencing e-readiness for COR is proposed based on diffusion of innovation theory (Rogers, 1995; Clarke 1999), and based on the detailed review of the literature of e-readiness in general. The framework pays particular attention to the core elements of e-readiness for COR to be present in any community, investor, nation, business etc. It is deemed necessary to adopt the idea of Environmental Theory ( see Gray, 1988; Cooke and Wallace, 1990; Nobes, 1998; Roberts et al, 1998; Radebaugh and Gray, 2002) in which the authors argued that accounting systems, including financial reporting practice in any country, are subject to internal and external factors. This framework also follows Molla (2004), and Molla and Licker (2002, and 2005). Molla and Licker (2005) followed interactionism as the theoretical root to build their model, as illustrated in Figure 1, which includes two major elements namely: perceived organizational e-readiness and perceived external e-readiness. The former is defined as managers' perception and evaluation of the degree to which they believe that their company has the awareness, resources, commitment, and governance to be ready to adopt e-commerce. The latter is the evaluation of the degree to which managers believe that market forces, government, and other supporting industries are ready to participate to support their companies to enter e-commerce. Tan et al. (2007) stated that Molla and Licker (2005) provided a comprehensive model as it includes both extensive external environmental and internal company issues.

\section{Please insert Figure 1 here}

This paper has adapted and extended Molla and Licker's (2005) perceived e-readiness model into the context of financial reporting practices, i.e. COR, as a first attempt to connect e-readiness and COR. This paper has utilised interactionism as a theoretical foundation to build the current framework. According to Molla and Licker (2005) interactionism joins the imperative theories of information technology (i.e. technological, organizational, social 
and political) into one dynamic theoretical approach which accepts that potentially all of these factors can influence information technology. This is akin to Xiao et al.'s $(1996,1997)$ contingency perspective which suggests that information technology does not imperatively impact upon an organization or particular practices but rather is subject to a variety of contingent factors (i.e. technological, cultural, economic, political, organizational and behavioural). Furthermore, Xiao et al. (2002) followed Xiao et al.'s $(1996,1997)$ approach when developing their framework addressing expected trends in COR, thus the methodological approach has been employed already elsewhere.

Finally, Molla and Licker's (2005) interactionism and Xiao et al.'s $(1996,1997)$ contingency perspective have equally contributed to the research methodology adopted for developing the proposed framework. As illustrated in Figure 1, Molla and Licker (2005) proposed their framework regarding e-readiness on the basis of interactionism. This posed the starting point for the current framework. After critically examining Molla and Licker's framework regarding financial reporting (see Gray, 1988; Nobes, 1998; Roberts et al, 1998; Radebaugh and Gray, 2002), Xiao et al's $(1996,1997)$ contingency perspective was used to integrate the contingent factors regarding e-readiness for COR. Employing this perspective posits that multi-perspective internal and external contextual issues can influence the e-readiness for COR.

\section{Research method}

In order to enrich the proposed framework, an extensive review was performed for a number of instruments for assessing e-readiness, as well as a further review of prior related accounting frameworks was performed. The main purpose of the latter review was to identify the potential factors to be included in the current framework. Following Molla and Licker (2005), it was decided to include a two-dimensional concept of e-readiness for COR, representing internal and external e-readiness constructs. This indicates that the e-readiness for COR is contingent upon both macro and micro levels. At the macro level, e-readiness for COR is subject to a country's environmental setting, e-infrastructure, and cultural influence, and is evaluated in accordance with the national benchmark. At the micro level, e-readiness for COR is subject to companies' internal issues: awareness, qualified human resources, business financial resources, technological resources, and governance.

To ascertain that error or repetition of factors (those sharing the same underlying concept) were reduced, and that the accuracy and validity of the proposed framework was ensured, the procedure suggested by Carlile and Christensen (2005) and also the procedures conducted by Molla and Licker (2005) were followed and performed in this paper. Carlile and Christensen (2005) suggest that different disciplines give different input for the same concept. Thus, they believe that the views of academics and professionals from differing backgrounds should be considered in developing a theory. Molla and Licker (2005) recommend that several procedures should be followed in developing an instrument which includes specifying the list of potential factors, purifying these factors through a pilot study, collecting feedback and additional information in order to make the framework parsimonious, and finally testing the validity and reliability of the proposed framework.

In this study, firstly, thirteen exploratory interviews and informal discussions were conducted with academics in the area of accounting and information technology and management information systems, regarding the potential factors to be included in the framework. Language and innovation were suggested to be included in the framework as internal factors in relation to human skills. Insecurity or trust as some call it, and discomfort, were suggested to be included as human attitude toward technology or as a sub-culture. Secondly, it was decided to carry out a pilot questionnaire survey to collect the perceptions of four different user-groups of COR: financial analysts, managers, bank credit officers and auditors, regarding the potential factors. The four different user groups were chosen as different disciplines in order to collect different inputs (Carlile and Christensen, 2005). Therefore, a questionnaire was designed and divided into 3 sections: The first section contains questions seeking general information on the respondents' demographic profile. The second section contains questions seeking general information on the respondent's technological profile. The third section contains a list of potential factors, with the definition for each factor, collected from the literature review and from the pilot study. The respondents were asked in the third section to determine the degree of importance of each factor using Likert-type five scales, where (1) referred to strongly important, and (5) to strongly unimportant. The first draft of this questionnaire was also piloted and then modified in light of the feedback of the thirteen academics, who were interviewed and asked to participate in this pilot.

\section{Analysis and Results}

The survey was carried out on the $20^{\text {th }}$ of August 2010 and continued until $20^{\text {th }}$ of September 2010. Initially, 400 copies of the questionnaire were distributed by hand through the researcher's students to a random sample of four different user-groups of COR: financial analysts, managers, bank credit officers and auditors. Overall, 155 
copies were fully completed and usably returned which represent a response rate of $38 \%$ of the entire population, considered favorably according to Al-Subaihi (2008). The 155 respondents consisted of the following: 20 Jordanian financial analysts, 35 academics in the area of business from Jordanian private and public universities, 75 managers and officers at a higher level from different companies located in Jordan and 25 auditors working in Jordan. The non-response bias test was performed by comparing the early responses with late responses. The results of Mann-Whitney $U$ test at the 5\% confidence level revealed that there are no significant differences between the two sets of respondents. The descriptive statistics such as frequencies and measures of central tendencies were adopted for data analysis in order to analyse the users' opinions collectively. The analysis of the survey results is reported in two sections: Respondents' demographic and technological profile and perceived importance of the potential factors

Respondents' demographic and technological profile: The first section of the current survey sought information on the demographic profile of respondents including their age, qualifications, work and experience in order to help in the analysis of the questionnaire responses. Results reveal that respondents were on average 36 years old and $100 \%$ with more than 3 years work experience, and possessed a degree in accounting or in business-related areas. Furthermore, the second section addressed their mobile and internet usage. The results of questions related to the respondents' technological background show that all respondents are heavy mobile and internet users. They also show a variation in the level and purposes of using the internet. One hundred per cent of the current respondents agreed on the reliability and the affordability of having a broadband internet connection at home. Finally, $78 \%$ of the current respondents had at least one account with facebook and/or twitter. This indicates that the current respondents are familiar in using the Internet and they are qualified to provide the information sought through answering the questionnaire.

Perceived importance of potential factors: In the final section of the questionnaire respondents were asked to indicate the degree of importance of each factor using Likert-type five scales, where (1) referred to strongly important, and (5) to strongly unimportant. To assess the importance of the proposed factors according to the participants' perceptions the average of the "strongly agree" and "agree" answers was computed. The results show that the average of participants' agreements regarding the appropriateness of each factor at the macro level of e-readiness for COR are 4.78 out of 5 for e-infrastructure, 3.56 out of 5 for culture, and for the internal issues: 4.3 out of 5 for awareness, 4.1 out of 5 for qualified human resources, 4.0 out of 5 for business financial resources, 3.8 out of 5 for technological resources, and 3.6 out of 5 for governance and commitment. Furthermore, 2.9 out of for cost benefits, market forces and company characteristics, and 2.8 out of 5 for technological regulation and sub-culture were identified. These factors were integrated with each other as illustrated in Figure 2.

\section{Please insert Figure 2 here}

A detailed discussion of these factors is provided next in order to set the developed framework in its literary context. Informed by various theories and following discussions, hypotheses are developed as an extension of the proposed framework. The benefit of these hypotheses is to demonstrate the usability of the e-readiness for COR framework, and to highlight its application as theoretical foundation for future research undertakings.

As transpires from Figure 2, both internal and external factors interact with each other to influence the e-readiness for COR in a country directly and indirectly. External factors include the societal culture and the infrastructure for electronic undertakings, for instance the ability to access the Internet quickly or even at all. These also reflect the existence or absence of technology regulation, and reflect actual market factors to be taken into consideration. Based on the participants' responses the actual infrastructure is ranked most important, followed by the cultural attitude towards technological and e-practices.

The internal factors refer to companies' structures and capabilities, such as human and technological resources, appropriate governance and other rule structures, cost-benefit of corporate reporting for the firm and the various company characteristics that determine whether companies will engage in corporate reporting. Most importantly ranked are awareness, human resources to undertake online reporting and financial resources available to do so.

The level of e-readiness for COR may be conditional upon the interaction between two or more of these factors. In other words, the level of e-readiness may be assessed as positive by one factor and negative by another. Further, the interaction between these factors may be at different levels from one country to another, which provides different driving forces behind intra-country developments and changes over time in the level COR's practices. This framework stresses the point that the form and content of COR at any time and in any place are subject to both endogenous and exogenous e-readiness factors, which are considered to instigate developments and changes in COR as well as in the managerial incentives for online reporting within a country. The external 
e-readiness or the environment e-readiness cause the differences in the COR practices from one country to another, as the review of the prior empirical surveys of COR revealed inconsistent results in different countries. This may be due to the differences in the environmental factors among these countries. For instance, Deller et al. (1999) found a variation across countries as $91 \%$ of US companies use the internet for investor relation activities whereas $72 \%$ and $71 \%$ of UK and German companies respectively do so. According to the international literature of accounting research, accounting practices including financial reporting, and here COR, in any country are shaped by dynamic environmental forces and factors (Gray, 1988; Nobes, 1998; Roberts et al., 1998; Radebaugh and Gray, 2002).

In the context of COR, e-infrastructure is also considered to be one of the main challenges for e-readiness in the previous e-readiness studies. The e-infrastructure includes: network infrastructure, access, affordability, reliability and speed and functionality. Culture was also found to be a barrier to adopt COR, and in this context, Xiao et al. (2002) stated that users might be reluctant to adapt to technological change. This can also be attributed to the users' culture. Ultimately, as Xiao et al. (2002) argue, the change in internet financial reporting is "conditional on cultural, economic, political, organizational and behavioural factors" (Xiao et al., 2002, p. 250). This leads to the first suggested hypothesis:

Hypothesis 1: e-readiness for COR is associated with external environmental factors such as e-infrastructure and culture.

Moving from the macro to more dynamic micro context, this framework states that market forces such as international trade and investments have an impact through requiring a global standardised communication system. Industry e-readiness such as telecommunications, financial, trust enablers and the IT industry, and their activities might affect the adoption of COR. These forces provide the choices and the room for managers' incentives to exceed their communication channels to disseminate additional information in order to satisfy local and international investors' desires. Technological regulations are also recognised in this framework as a valuable and relevant factor to determine the implementation of COR in any country. In this context Molla and Licker (2005) argued that e-regulations in any country allow electronic settlement of e-commerce. This framework brings up the internal e-readiness as an important main domain for COR's e-readiness. Following Molla and Licker's (2005) internal companies' issues, such as awareness, commitment, qualified human resources, financial resources, technological resources and governance, determine the implementation of COR in any company. The following shows the definition and the description of these variables as adapted from Molla and Licker's (2005) model in relation to e-readiness for COR.

Company's awareness represents how COR elements are perceived by the environment; comprehension of their meaning through an understanding of COR as a communication system and its benefits and threats and projection of the future trends. Company's commitment reflects enough energy and support for adopting COR from all corners inside the company and especially from the strategic apex. It refers to having a clear-cut COR vision and strategy champion by top management. Human resources refer to the availability of employees with adequate experience, education, skills and exposure to COR information sub-culture. Technical knowledge, skills and understanding of the employees and their attitude towards new technology are considered vital in COR adoption. Technological resources refer to the company's extent of computerization, the flexibility of existing systems and experience with network based applications. Company's resources cover a wide range of capabilities and most of the intangible assets of the company. These include the openness of organizational communication; risk taking behaviour, existing business relationships, and funding to finance COR activities (Molla and Licker, 2005, pg.882). This leads to the second hypothesis:

Hypothesis 2: e-readiness for COR is associated with internal company factors such as awareness, commitments, human resources, company resources, governance and sub-culture.

Furthermore, economics-based theories such as agency theory, capital need theory, and signalling theory often explain the variation in the level of COR across samples of companies by reference to the cost-benefit analysis and company characteristics, such as company size, industry type, structure of ownership and managerial performance. In this context, Xiao et al. (2004) stated that the level of COR's implementation among companies could be due to company characteristics often suggested by economics-based theories. Hypothesis 3 theorises this relationship:

Hypothesis 3: e-readiness for COR is associated with internal company characteristics such as size, industry type, structure of ownership and managerial performance.

Finally, it is important to note that, the level of COR's adoption among countries differs according to these internal and external e-readiness factors. For instance, emerging economies, in comparison to developed 
economies, often lack the necessary financial, legal, and physical infrastructures for the development of COR. Emerging economies often have different cultures and business philosophies, which limit the applicability of any technology (Tan et al., 2007) and COR is considered as one. The adoption of COR can take different forms and complexities over different generations, thus in order to make the proposed framework tractable, it was deemed necessary to differentiate between the earlier generation of COR adoption and the advanced version. This is consistent with Hedlin's (1999) three generations of COR: 1) early generation - establishing a Web presence: at this stage companies' websites contain general company information of little interest to investors. 2) Intermediate generation - using the Internet to communicate investor information: this generation company wishes to communicate with various groups through adding electronic versions of paper-based annual reports. 3) Advanced generation - taking advantage of the unique features and possibilities of the medium: in this generation companies' websites are not just alternative tools for distributing traditional print-based annual reports, but companies take advantage of the unique features and possibilities the Internet.

\section{Conclusion and implications}

Although the Internet and COR emerged as a new communication system around the world, the adoption and utilization of COR is faced with a number of challenges. The main contribution of this paper is the attempt at a theoretical contribution in form of the framework of e-readiness for COR. This current framework highlights the relevance of external and internal challenges that might slow the developments of COR. The e-environment or e-infrastructure, culture, financial and human resources as well as sub-culture and legal factors restrain the adoption of COR. These issues should be considered at country and company levels in order to enhance a better adoption of COR. International accounting research still needs to address the issue of COR's e-readiness. However, it is important to note that, while this framework puts external and internal factors as two main dimensions to determine the e-readiness for COR, the influence of each dimension could be different in a different country setting. For instance, the external environment plays the major role in COR adoption in one country whereas the internal factors play the major role in other country. Therefore, an investigation e-readiness for COR and testing the current framework across countries is an interesting area of study. The possible research approaches are likely to involve some sort of survey or investigation of companies and different users groups. In that case, an investigation covering several developed and developing countries may be more meaningful.

\section{References}

Al-Hayale, T. (2010). Financial reporting on the internet in the Middle East: the case of Jordanian industrial companies. International Journal of Accounting and Finance, Vol. 2, No. 2, pp. 171-191. http://dx.doi.org/10.1504/IJAF.2010.032087

Al-Htaybat, K. and Napier, C. (2006). Online corporate financial reporting in developing countries: the case of Jordan. paper presented at the BAA Annual Conference, Portsmouth University, Portsmouth.

Al-Solbi, A and Mayhew, P. (2005). Measuring e-Readiness Assessment in Saudi Organizations. [Online] Available: http://www.mgovernment.org/resurces/euromgov2005/PDF/48_131A

Al-Subaihi, A. A. (2008). Comparison of Web and Telephone Survey Response Rates in Saudi Arabia. The Electronic Journal of Business Research Methods, Vol. 6, No. 2, pp. 12-132.

Aly, D., Jon, S., and Hussainey, K. (2010). Determinants of corporate internet reporting: evidence from Egypt. Managerial Auditing Journal, Vol. 25, No. 2, pp.182-202. http://dx.doi.org/10.1108/02686901011008972

Andrikopoulos, A. (2007). Financial reporting practices on the internet: the case of companies listed in the Cyprus Stock Exchange. Working paper, University of the Aegean, Greece. [Online] Available: http://ssrn.com/abstract=999183 (10 May 2011)

Aziz, N.M. and Salleh, H. (2011). Managing Organisation/Business Readiness towards IT/IS implementation: a model comparison. Australian Journal of Basic and Applied Sciences, Vol. 5, No. 2, pp. 215-221.

Beig, L. (2007). Adoption a Proper Tool for E-Readiness Asessment in Developing Countries (Case Studies: Iran, Turkey and Malaysia). Journal of Knowledge Economy \& Knowledge Management, Vol. II Spring.

Bozcuk, A., Arzova, S. B., \& Aslan, S. (2008). Internet financial reporting: the case of Turkey. Akdeniz University, Antalya, Turkey. [Online] Available: http://ssrn.com/abstract=1490523 (1 August 2010)

Carlile, P.R. and Christensen, C.M. (2005). The cycles of theory building in management research. Version 6.0, Working paper, Innosight. [Online] Available: www.innosight.com/documents/Theory\%20Building.pdf 
Choucri, N., Maugis, V., Madnick, S., and Siegel, M. (2003). E-readiness for what?. A Research and Education Initiative at the MIT Sloan School of Management. [Online] Available: http://ebusiness.mit.edu/research/papers/177_Choucri_GLOBAL_eREADINESS.pdf

CID (Centre for International Development), Harvard University. (2006). Readiness for the Networked World-A Guide for Developing Countries. [Online] Available: www.readinessguide.org

Clarke, R. (1999). A primer in diffusion of innovations theory. [Online] Available: http://www.anu.edu.au/people/Roger.Clarke/SOS/InnDiff.html

Cooke, T.E., and Wallace, O. (1990). Financial Disclosure Regulation and its Enviroment: A Review and Further Analysis. Journal of Accounting and Public Policy, Vol. 9, pp.79-110. http://dx.doi.org/10.1016/0278-4254(90)90013-P

Curuk, T. (1999). An Analysis of Factors influencing Accounting Disclosure in Turkey, Unpublished Doctoral Thesis, University of Exeter, UK.

Dada, D. (2006). E-readiness for Developing Countries: Moving the Focus from the Environment to the Users. EJISDC, Vol. 27, No. 6, 1-14.

Deller, D., Stubenrath, M. and Weber, C. (1999). A survey on the use of the Internet for investor relations in the USA, UK and Germany. European Accounting Review, Vol. 8, No. 2, pp. 351-64. http://dx.doi.org/10.1080/096381899336087

Desoky, A. (2009). Company Characteristics as Determinants of Internet Financial Reporting In Emerging Markets: The Case of Egypt. Accounting in Emerging Economies: Research in Accounting in Emerging Economies, Vol. 9, pp. 31-71. http://dx.doi.org/10.1108/S1479-3563(2009)0000009004

Despina. A., and Demetrios., P. (2009). The web-based financial reporting adopted by the listed companies in the Athens Stock Exchange. Journal of Modern Accounting and Auditing, Vol. 5, No. 7, pp. 7-20.

Ettredge, M., Richardson, V. J. and Scholz, S. (2002). Dissemination of information for investors at corporate web sites. Journal of Accounting and Public Policy, Vol. 21, pp. 357-369. http://dx.doi.org/10.1016/S0278-4254(02)00066-2

Gray, S. J. (1988). Towards a theory of cultural influence on the development of accounting systems internationally. ABACUS, Vol. 24, No. 1, pp. 1-15. http://dx.doi.org/10.1111/j.1467-6281.1988.tb00200.x

Hanafi, S.R.B.M., Kasim, M.A.B., Ibrahim, M.K.B., and Hancock, D.R. (2009). Business reporting on the Internet: development of a disclosure quality index. International Journal of Business and Economics, Vol. 8, No. 1, pp. 55-79.

Hedlin, P. (1999). The Internet as a vehicle for investor relations: the Swedish case. European Accounting Review, Vol. 8, No. 2, pp. 373-81. http://dx.doi.org/10.1080/096381899336104

Hofstede, G., and Bond, M.H. (1988). The Confucius connection: from cultural roots to economic growth. Organizational Dynamics, Vol. 16, No. 4, pp.5-21. http://dx.doi.org/10.1016/0090-2616(88)90009-5

Jones, M.J. and Xiao, J.Z. (2003). Internet reporting: current trends and trends by 2010. Accounting Forum, Vol. 27, No. 2, pp. 132-165. http://dx.doi.org/10.1111/1467-6303.00099

Keoduangsine, S. and Goodwin, R. (2009). Measuring E-Readiness Assessment : The case of Laotian Organisations. The 6th International Conference on Information Technology and Applications (ICITA 2009). [Online] Available: http://www.icita.org/papers/23-la-keoduangsine-150.pdf

Lai, S. C., Lin, C., Li, H. C., \& Wu, F. H. (2010). An Empirical Study of the Impact of Internet Financial Reporting on Stock Prices. International Journal of Digital Accounting Research, Vol. 10, pp. 1-26. http://dx.doi.org/10.4192/1577-8517-v10_1

Marston, C. and Polei, A. (2004). Corporate reporting on the Internet by German companies. International Journal of Accounting Information Systems, Vol. 5, pp. 285-311. http://dx.doi.org/10.1016/j.accinf.2004.02.009

Marston, C. (2003). Financial reporting on the Internet by leading Japanese companies. Corporate Communications, Vol. 8, No. 1, pp. 23-27. http://dx.doi.org/10.1108/13563280310458894

McConnell International. (2000-2002). Qualitative Indices, Connectivity, E-Leadership, Information Society, Human Capital, E-Business Climate. 
Molla, A. (2004). The Impact of eReadiness on eCommerce Success in Developing Countries: Firm-Level Evidence, paper No. 18, Development Information. Working Paper published by Institute for Development Policy and Management University of Manchester. [Online] Available: http://idpm.man.ac.uk/publications/wp/di/index.shtml

Molla, A. and Licker, P.S. (2002). PERM: A model of e-commerce adoption in developing countries. In Khosrowpour, M. ed. Issues and Trends of Information Technology.

Molla, A. and Licker, P.S. (2005). eCommerce adoption in developing countries: a model and instrument. Information \& Management, Vol. 42, pp. 877-899. http://dx.doi.org/10.1016/j.im.2004.09.002

Momany, M., \& Al-Shorman S. (2006). Web-Based Voluntary Financial Reporting of Jordanian Companies. International Review of Business Research Papers, Vol. 2, No.2, pp. 127-139.

Nobes, C. (1998). Towards a General Model of the Reasons for International Differences in Financial Reporting. $A B A C U S$, Vol. 34, No 2, pp, 162-187. http://dx.doi.org/10.1111/1467-6281.00028

Oyelere, P., Laswad, F. and Fisher, R. (2003). Determinants of Internet financial reporting by New Zealand listed companies. Journal of International Financial Management and Accounting, Vol. 14, No. 1, pp. 26-63. http://dx.doi.org/10.1111/1467-646X.00089

Radebaugh, L. H., and Gray S. J. (2002). International accounting and multinational enterprises, $5^{\text {th }}$ Edition, J. Wiley, New York.

Rizk, N. (2004). E-readiness Assessment of Small and Medium Enterprises in Egypt: A Micro Study. Topics in Middle Eastern and North African Economies, Vol. 6, 1-23.

Roberts, C., Weetman, P. and Gordon, P. (1998). International Financial Accounting: A Comparative Approach. Financial Times Pitman Publishing, London.

Rogers, E. M. (1995). Diffusion of Innovations. New York, The Free Press.

Tan, J., Tyler, K. and Manica, A. (2007). Business-to-business adoption of eCommerce in China. Information \& Management, Vol. 44, pp. 332-351. http://dx.doi.org/10.1016/j.im.2007.04.001

Verma., D. (2010). Web-based Business Reporting in Indian Corporate Sector. Journal of Knowledge Management Practice, Vol. 11, Special Issue 1.

Wolcott, P., Press, L. and McHenry, W. (2001). A Framework for Assessing the Global Diffusion of the Internet. Journal of the Association for Information Systems, Vol. 2, No. 6, pp. 1 - 50. [Online] Available: http://aisel.aisnet.org/jais/vol2/iss1/6, (30 November 2010)

Xiao, J.Z., Dyson, J. and Powell, P. (1996). The impact of information technology on corporate financial reporting: a contingency perspective. British Accounting Review, Vol. 28, No. 3, pp. 203-27. http://dx.doi.org/10.1006/bare.1996.0015

Xiao, J.Z., Jones, M.J. and Lymer, A. (2002). Immediate trends in Internet reporting. European Accounting Review, Vol. 11, No. 2, pp. 245-275. http://dx.doi.org/10.1111/1467-6303.00099

Xiao, J.Z., Yang, H. and Chow, C.W. (2004). The determinants and characteristics of voluntary Internet-based disclosures by listed Chinese companies. Journal of Accounting and Public Policy, Vol. 23, pp. 191-225. http://dx.doi.org/10.1016/j.jaccpubpol.2004.04.002

Table 1. Environmental factors influencing financial reporting practices

Countries' External Factors
- International trade
- Regional economy
- International regulations
- Technology factors
- Others

Countries' External Factors

- International regulations

- Others

\author{
Countries' Internal Factors \\ - Economic developments \\ - Political systems \\ - Internal regulations, legal and taxation system \\ - Capital market \\ - Accounting professionals \\ - Level of education and research \\ - Culture, religion, language, history and others
}




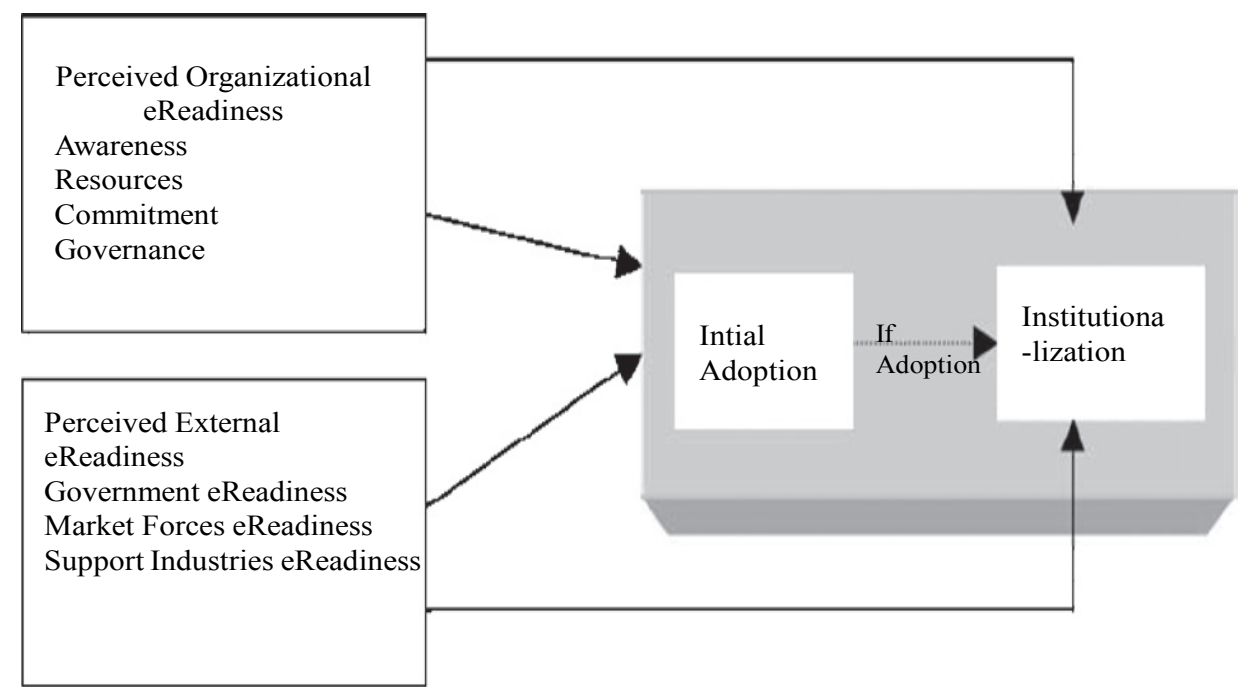

Figure 1. The perceived e-readiness model of Molla and Licker (2005, p. 881)

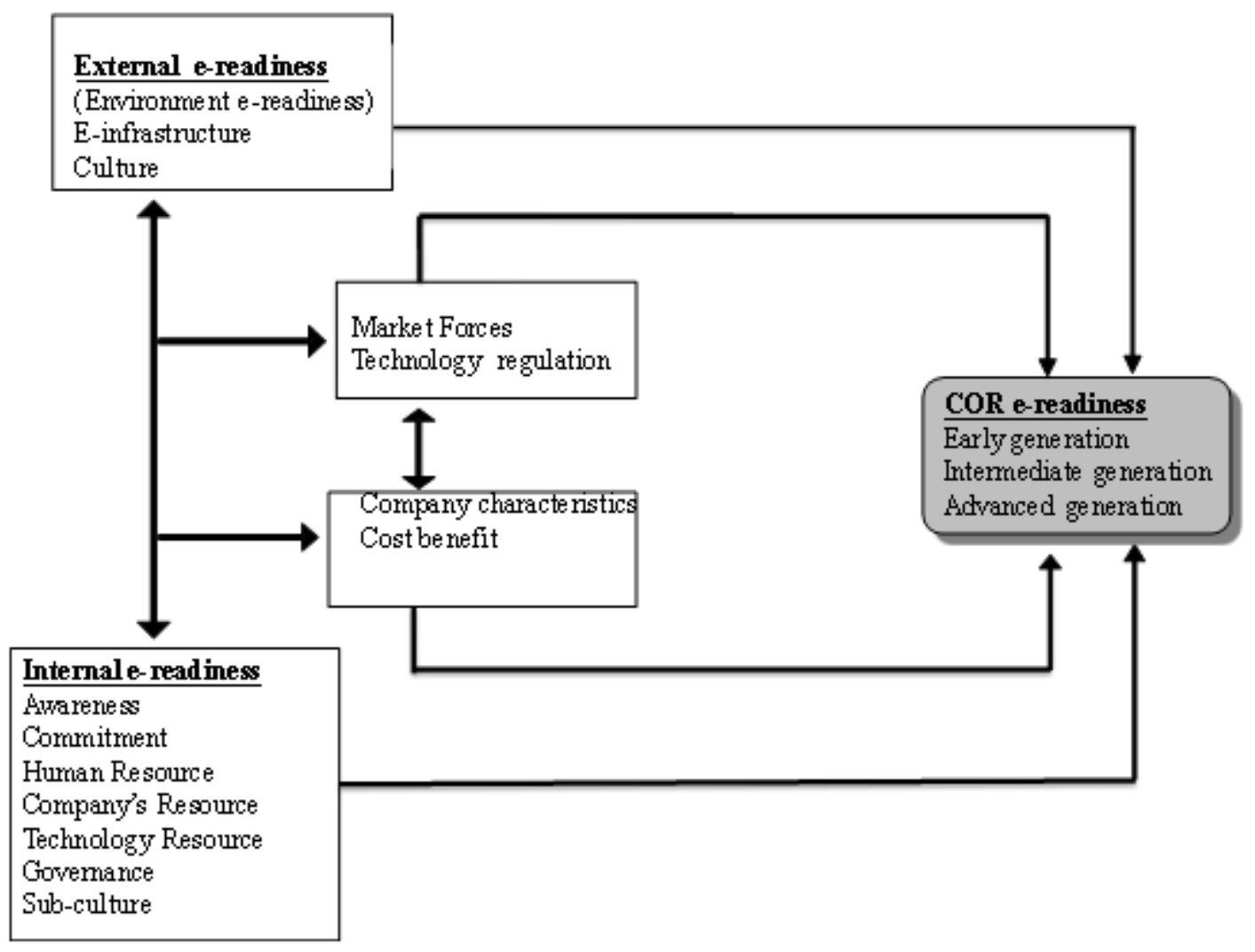

Figure 2. A Framework of factors influencing e-readiness for COR 